\title{
REVISÃO: A FIXAÇÃO BIOLÓGICA DE NITROGÊNIO E SUA APLICAÇÃO PARA UMA AGRICULTURA SUSTENTÁVEL
}

\author{
Leandro Israel da Silva ${ }^{1}$ \\ ${ }^{1}$ Bacharel em Ciências Biológicas, Programa de Pós Graduação em Microbiologia Agrícola, \\ Universidade Federal de Lavras (UFLA), Lavras, Minas Gerais.
}

DOI: $10.47094 /$ ICONNECA.2021/11

\begin{abstract}
RESUMO
A agricultura é uma atividade fundamental a vida. Todavia, a demanda agrícola para os próximos anos é muito grande, sendo estimado a necessidade de aumento de cerca de $60 \%$ da capacidade produtiva. Entretanto, o desenvolvimento agrícola muitas vezes ameaça à integridade ambiental, principalmente a aplicação indiscriminada de agroquímicos. Este trabalho objetiva elucidar e demonstrar a aplicação de microrganismos fixadores de nitrogênio como vetores de uma agricultura sustentável. Assim, foi realizada uma revisão literária dos assuntos correlacionados em diferentes plataformas de pesquisa. Os microrganismos envolvidos na fixação biológica de nitrogênio são conhecidos como diazotróficos, eles contribuem com cerca de $64 \%$ do nitrogênio fixado em escala global e assimilado pelas plantas por ser um macronutriente indispensável. Pesquisas recentes demonstram a significância deles no desenvolvimento de culturas como soja, feijão e trigo. Existe também um fomento nacional na elaboração de bionsumos, o que junto as perspectivas do mercado apontam um futuro ecologicamente sustentável.
\end{abstract}

PALAVRAS-CHAVE: Bioinsumos. Diazotróficos. Desenvolvimento sustentável.

ÁREA TEMÁTICA: Biotecnologia.

\section{INTRODUÇÃO}

A agricultura é uma atividade fundamental a vida, entretanto, muitas vezes a aplicação de defensivos agrícolas é realizada de maneira indiscriminada. Isto implica em impactos severos nas condições ecossistêmicas, principalmente no solo e água, para a biota natural e até para a saúde do trabalhador e consumidor (PIGNATI, 2018).

Recentemente microrganismos promotores de crescimento têm sido utilizados como vetores do desenvolvimento sustentável com a fabricação de bioinsumos. Existem microrganismos conhecidos como diazotróficos que são capazes de fixar o nitrogênio atmosférico e disponibilizá-los as plantas a partir da enzima nitrogenase (PATIL et al., 2017). Diversas culturas agrícolas sobretudo de leguminosas utilizam destes microrganismos uma vez que demonstram um potencial interessante 
no crescimento e acúmulo da biomassa vegetal (FILIPINI et al, 2017; GUPTA et al, 2019; WANG et al, 2020).

Este trabalho objetiva elucidar e demonstrar a aplicação de microrganismos fixadores de nitrogênio como vetores de uma agricultura sustentável a parir da revisão da literatura recente. Da mesma maneira é pretendido demonstrar como estes microrganismos pode integrar a formulação de bioinsumos e contribuir na perpetuação dos recursos para as gerações futuras.

\section{METODOLOGIA}

Para realizar esta revisão foi feita uma pesquisa preliminar na plataforma ScienceDirect (https://www.sciencedirect.com/) consultado o termo chave "Nitrogen Fixing Bacteria" (Bactérias fixadoras de nitrogênio) em artigos publicados nos últimos cinco anos, assim resultando em 8,950 trabalhos relacionados. A partir disto foi construído um mapa de correlação a partir das palavras chave mais frequentes no programa VOSviewer, onde foram constatados os principais tópicos de pesquisa referentes a área na atualidade. Com isso foram realizadas novas pesquisas em plataformas digitais para contemplar os assuntos relacionados.

Além disso, deve-se destacar que, na elaboração deste artigo, por se tratar de pesquisas bibliográficas com múltiplas fontes de informação (Science Direct, Google Scholar, Research Gate, entre outros) foram observados os parâmetros da pesquisa bibliográfica, descritiva e dedutiva e qualitativa. Foi feita a procura de trabalhos publicados na região, doutrinas ambientais, notícias e análise das leis e regulamentações vigentes que abrangem o conteúdo.

\section{FUNDAMENTAÇÃO TEÓRICA}

A agricultura constitui a base da subsistência para cerca de $40 \%$ da população global, sendo uma atividade fundamental para a produção de alimentos, combustíveis e matéria prima. Além disso assegura o sustento para o crescente número de mais de 7 bilhões de habitantes do planeta (RAMANKUTTY et al., 2018). Alexandratos e Bruinsma (2012), estimam que a população global irá crescer 35\% até 2050 e isto exigirá o aumento de $60 \%$ da produção agrícola em relação a produção atual. Tomando como base o consumo de leguminosas é visto a exemplo que um habitante brasileiro consume em média $17 \mathrm{~kg}$ de feijão por ano (MAPA, 2018).

Para suprir está demanda o modelo agrícola atual depende da utilização de diversos insumos agroquímicos. Na maioria das vezes é realizada a adubação com nutrientes, sobretudo Nitrogênio, Fósforo e Potássio (NPK) onde é observada a extrema dependência brasileira na importação destes fertilizantes (GALEMBECK e SANTOS, 2019). Contudo, além de terem um elevado custo de fabricação, estes produtos são facilmente imobilizados e lixiviados nos solos perdendo sua eficácia e de maneira mais grave acarretando desequilíbrios socioambientais principalmente devido à falta 
de cautela durante a aplicação, exemplos como processos de eutrofização e poluição de corpos hídricos podem ser citados (ADEOSUN et. al., 2020; HAMMERSCHMITT e LOPES, 2020). Sendo assim práticas agrícolas mais sustentáveis devem ser implementadas, visando diminuir os impactos ecológicos e garantindo a perenidade dos recursos futuros.

$\mathrm{O}$ nitrogênio $(\mathrm{N})$ é um nutriente fundamental às plantas. $\mathrm{O}$ macronutriente é constituinte das clorofilas, suas concentrações ótimas aumentam a produção e durabilidade foliar consequentemente otimizando o processo fotossintético. Sua presença beneficia a absorção de outros nutrientes como fósforo e potássio e a qualidade final dos frutos é mediada também pela abundância deste (AHMAD et al., 2009; BLOOM, 2015). Em contrapartida a deficiência de nitrogênio acarreta a diminuição da vitalidade das folhas por clorose, os botões florais podem se tornar insustentáveis e também pode ocorrer a redução da biomassa vegetal devido a insuficiência fotossintética (LEGHARI et al., 2016; HUANG et al., 2020).

Todavia o nitrogênio presente na atmosfera não é prontamente viável para a absorção pelos vegetais devido à forte interação de sua ligação tripla que o estabiliza em sua forma gasosa (PATIL et al., 2017). A maneira mais proveitosa para a fixação do nitrogênio é mediada biologicamente por procariotos denominados diazotróficos, este processo é conhecido como fixação biológica de nitrogênio (FBN) e pode ocorrer com os microrganismos em simbiose ou em vida livre.

A FBN representa por si só o rendimento de cerca de $64 \%$ do nitrogênio fixado em escala global, ocorrendo em florestas (24\%), áreas agrícolas (10\%) e nos oceanos (30\%) (PATIL et al., 2017). O processo ocorre exclusivamente a partir do complexo catalítico da enzima nitrogenase. A reação anaeróbica acontece com a ligação do $\mathrm{N}_{2}$ no complexo enzimático, que a partir de proteínas metálicas realizam a redução do nitrogênio gasoso possibilitando a hidrólise de sua tripla ligação e sua conversão a amônia $\left(\mathrm{NH}_{3}\right)$ a qual posteriormente é convertida por outros microrganismos do solo à amônio $\left(\mathrm{NH}_{4}\right)$, nitrato $\left(\mathrm{NO}_{3}\right)$ e nitrito $\left(\mathrm{NO}_{2}\right)$ formas assimiláveis pelas plantas (MARINO e HOWARTH, 2009; KRONECK e TORRES, 2014; VICENTE e DEAN, 2017).

A diversidade dos diazotróficos também é algo muito relevante. Gupta e colaboradores (2019) identificaram diversos taxa destes microrganismos interagindo com gramíneas presentes em solos agrícolas a partir do sequenciamento do gene NifH (precursor da nitrogenase). Foram constatados representantes dos gêneros Azospirillum, Bradyrhizobium, Burkholderia, Clostridium, Methylobacterium, Pelobacter e Polaromonas e isso demonstra que muitos microrganismos presentes no solo contribuem para acumulação do nutriente e sua posterior utilização pelas plantas.

A utilização de microrganismos promotores de crescimento em plantas tem se provado benéfica em inúmeros estudos. Para a soja (Glycine max L.), foi visto que a utilização de diferentes estirpes de Bradyrhizobium aumentou o teor de nitrogênio nos grãos onde em duas localizações experimentais obtiveram uma assimilação máxima de $404 \mathrm{Kg} / \mathrm{ha} \mathrm{e} 165 \mathrm{Kg} / \mathrm{ha}$, os controles não inoculados nessas mesmas localizações contaram com o teor de nitrogênio de 156,88 e $80,90 \mathrm{Kg} /$ ha respectivamente. Desta forma claramente é possível observar o efeito acumulativo dos microrganismos na fixação do nitrogênio. (STAJKOVIĆ-SRBINOVIĆ et al., 2020). 
Wang e colaboradores (2020), evidenciaram o efeito benéfico da promoção de crescimento proporcionadas por bactérias em trigo (Triticum sp. L.). A gramínea foi cultivada com uma combinação de bactérias composta por Bacillus sp., Agrobacterium tumefaciens, Klebsiella pneumoniae, Pseudomonas sp. e Klebsiella variicola, foi observado que o consórcio possibilitou o aumento da hidrólise alcalina de nitrogênio (49.46\%), e aumentou a disponibilidade de fósforo ( $99.1 \%)$ e potássio no solo (19.38\%), consequentemente o conteúdo de N, P, K das plantas foi avaliado em 97.7\%, 96.4\% e $42.1 \%$, respectivamente. Os autores concluíram que o uso destes microrganismos pode reduzir a demanda de fertilizantes químicos em até $25 \%$.

Filipini e colaboradores (2020) realizaram testes com diferentes formas de aplicação de um co-inóculo microbiano em feijão (Phaseolus vulgaris L). A aplicação que teve melhores resultados era caracterizada pela aplicação de Rhizobium tropici e Azospirillum brasilense nas sementes em conjunto com a aspersão foliar da última. Foi constatado que a aplicação do consórcio microbiano contribuiu para o incremento da biomassa dos ramos, as plantas inoculadas chegam em média a $70 \mathrm{~g}$ enquanto o controle sem inoculação apresenta $30 \mathrm{~g}$. De forma semelhante ocorreu um acúmulo no teor de nitrogênio onde os tratamentos com microrganismos chegaram a um acúmulo de $2 \mathrm{~g} / \mathrm{planta}$ enquanto o controle contava com aproximadamente $0,7 \mathrm{~g} /$ planta.

De forma recorrente surgem novas sansões que beneficiam a interação e o desenvolvimento de novas tecnologias ecologicamente viáveis, uma delas é o decreto ${ }^{\circ} 10.375$, de 26 de maio de 2020 que institui o Programa Nacional de Bioinsumos e o Conselho Estratégico do Programa Nacional de Bioinsumos (BRASIL, 2020). Por definição do decreto bioinsumos são produtos, tecnologias ou processos de origem animal, vegetal ou microbiana e que interfiram positivamente no desenvolvimento de processos agrícolas e florestais. Além disso o programa incentiva o firmamento de parcerias públicas e privadas para o desenvolvimento de bionsumos, e estabelece estruturas necessárias para suportar a sua produção segundo as boas práticas agrícolas. A utilização de bioinsumos enquadra o Brasil em sua terceira onda agrícola. O setor cresce a uma taxa anual superior a $10 \%$ e movimenta cerca de R\$ 1.0 bilhão por ano (CANAL RURAL 2020).

\section{CONSIDERAÇÕES FINAIS}

Como foi visto os microrganismos, sobretudo os fixadores de nitrogênio são vetores imprescindíveis para a edificação de uma agricultura sustentável e para a consolidação de um desenvolvimento ecologicamente viável a longo prazo. Com o aumento e aplicação de novas técnicas aliadas a uma progressão científica no assunto os próximos anos podem ser promissores para a formulação de novos produtos biológicos. Mantidas as devidas proporções, os bioinsumos provavelmente não substituíram a necessidade da aplicação de fertilizantes químicos, entretanto eles podem diminuir significamente a magnitude de aplicação deles no ambiente reduzindo os impactos mais severos. 
A legislação para a aprovação de novos produtos e a aceitação deles pelos produtores podem ser os desafios que mais limitam os bioinsumos. Entretanto a própria progressão do mercado evidencia que está ocorrendo sim uma crescente na demanda e consequentemente na aplicação destes produtos, assim é visto que um futuro mais sustentável está sendo construído a passos lentos, mas não finitos.

\section{PRINCIPAIS REFERÊNCIAS}

BRASIL. Decreto no 10.375, de 27 de maio de 2020. Institui o Programa Nacional de Bioinsumos e o Conselho Estratégico do Programa Nacional de Bioinsumos. Diário Oficial da União, [S. 1.], ed. 100, p. 105, 2020.

FILIPINI, L.D., PILATTI, F.K., MEYER, E. Application of Azospirillum on seeds and leaves, associated with Rhizobium inoculation, increases growth and yield of common bean. Arch Microbiol 203, p. 1033-1038, 2021.

GUPTA, V. V. S. R., ZHANG, B. PENTON, C. R., YU, J., TIEDJE, J. M. Diazotroph Diversity and Nitrogen Fixation in Summer Active Perennial Grasses in a Mediterranean Region Agricultural Soil.Frontiers in Molecular Biosciences, v. 6. 115p., 2019.

PATIL, B. S., HESSEL, V., SEEFELDT, L. C., DEAN, D. R., HOFFMAN, B. M., COOK, B. J., MURRAY, L. J. Nitrogen Fixation, Weinheim: Ullmann's Encyclopedia of Industrial Chemistry p. $1-21,2017$.

STAJKOVIĆ-SRBINOVIĆ, O., DE MEYER, S. E., KUZMANOVIĆ, D., DINIĆ, Z., DELIĆ, D., Willems, A. Soybean seed chemical composition as influenced by Bradyrhizobium inoculation in soils with elevated nickel concentrations. Applied Soil Ecology, 2020. 